\title{
PEMODELAN DISTRIBUSI FREKWENSI TIME HEADWAY LALU LINTAS DI WILAYAH JALAN BERBUKIT
}

\author{
Rizky Indra Utama ${ }^{1}$, Purnawan ${ }^{2}$, dan Hendra Gunawan ${ }^{3}$
}

\begin{abstract}
ABSTRAK
Time headway merupakan besaran mikroskopik arus lalu lintas yang sangat penting kegunaannya dalam analisis dan perencanaan suatu sistem transportasi. Pentingnya time headway, khususnya dalam microscopic traffic simulation, mendorong perlunya penentuan standar nilai yang dapat digunakan untuk keperluan praktis. Penelitian ini bertujuan untuk mengetahui model distribusi time headway yang sesuai untuk data hasil penelitian di wilayah jalan berbukit. Penelitian mengambil data arus lalu lintas pada ruas jalan Padang Panjang- Bukittinggi Km. 5. Pengumpulan data primer dilakukan dengan menggunakan handycam. Pengolahan data pengamatan menggunakan Software Stop Data Program. Untuk mendapatkan goodness of fit dari model distribusi data pengamatan yang cocok dengan distribusi teoritis, maka dilakukan Kolmogorov Smirnov Test (K-S Test) dengan menggunakan Software EasyFit, sehingga dihasilkan model yang cocok dengan kondisi wilayah jalan berbukit. Dari analisis didapatkan hasil sebagai berikut: model distribusi terbaik hasil uji time headway individual Hari Sabtu pada jalur tanjakan didapatkan model hasil uji yang terbaik adalah model Beta dengan nilai $\alpha_{1}=2,290, \alpha_{2}=7,668, a=4,615 \times 10^{-17}, b=16,809$, pada jalur turunan didapatkan model hasil uji yang terbaik adalah model Weibull dengan nilai $\alpha=1,546, \beta=3,551, \gamma=0$. Model distribusi terbaik hasil uji time headway individual Hari Minggu pada jalur tanjakan didapatkan model hasil uji yang terbaik adalah model Beta dengan nilai $\alpha_{1}=2,217, \alpha_{2}=6,626, a=2,895 \times 10^{-16}, b=15,046$, untuk jalur turunan didapatkan model hasil uji yang terbaik adalah model Cauchy dengan nilai $\sigma=0,703$ dan $\mu=2,937$. Time headway rata-rata Hari Sabtu pada jalur tanjakan diperoleh 3,86 detik, pada jalur turunan didapatkan 3,17 detik. Selanjutnya time headway rata-rata Hari Minggu pada jalur tanjakan didapatkan 3,77 detik, pada jalur turunan diperoleh 3,21 detik.
\end{abstract}

Kata kunci : Time Headway, Goodness Of Fit Test, Model Distribusi

\section{PENDAHULUAN}

\section{I.1 Latar Belakang}

Time headway merupakan besaran mikroskopik arus lalu lintas yang sangat penting kegunaannya dalam analisis dan perencanaan suatu sistem transportasi. Beberapa kegunaan time headway diantaranya berkaitan dengan masalah analisis keselamatan transportasi, tingkat pelayanan jalan dan fasilitas lainnya, perilaku pengendara dan kapasitas suatu prasarana transportasi.Time headway minimum berguna agar lalu lintas yang berjalan tetap aman dan tidak terjadi tabrakan antar kendaraan yang beriringan. Time headway antar kendaraan yang saling beriringan juga menunjukkan tingkat kualitas pelayanan dari jalan yang bersangkutan. Begitu juga time headway

\footnotetext{
${ }^{1}$ Mahasiswa Pascasarjan Teknik.Sipil, rizkyindrautama@gmail.com

${ }^{2}$ Dosen Pascasarjana Teknik Sipil, purnawan@ft.unand.ac.id

${ }^{3}$ Dosen Pascasarjana Teknik Sipil, hendra@ft.unand.ac.id
} 
merupakan ukuran yang dipakai untuk melihat seberapa besar kapasitas suatu jalan dengan melihat distribusi time headway yang terjadi.

Topografi jalan berbukit atau menanjak dengan kondisi arus lalu lintas dari berbagai jenis kendaraan berat dan kendaraan ringan memiliki pola distribusi berbeda dengan kondisi jalan datar. Oleh sebab itu perlu dilakukan studi mengenai pemodelan distribusi time headway lalu lintas pada kondisi wilayah jalan berbukit atau jalan menanjak.

\section{I.2 Rumusan Masalah}

Mengacu pada permasalahan diatas, yang akan dibahas pada penelitian ini adalah model distribusi apakah yang menggambarkan kondisi di wilayah jalan berbukit ?

\section{I.3 Tujuan Penelitian}

Adapun tujuan penelitian ini adalah untuk memilih model distribusi time headway yang sesuai untuk data hasil penelitian di wilayah jalan berbukit.

\section{I.4 Manfaat Penelitian}

Adapun manfaat yang dapat diambil dari penelitian ini, antara lain: (1)mengetahui model distribusi time headway lalu lintas di wilayah perbukitan atau pada kondisi jalan menanjak, (2)data dan model distribusi time headway dapat digunakan untuk membuat simulasi arus lalu lintas pada kondisi jalan menanjak atau di wilayah perbukitan.

\section{I.5 Batasan Masalah}

Untuk menyederhanakan permasalahan, maka berikut ini diberikan batasan masalah yaitu: (1)penelitian hanya mengambil sampel di Jalan Padang Panjang - Bukittinggi Km 5, (2)sampel diambil selama jam-jam tertentu yang diasumsikan memiliki arus kendaraan yang padat (peak hour), walau tidak harus jenuh, dan tidak padat (non peak hour), (3)untuk ruas jalan tersebut, kendaraan sepeda motor dan tak bermotor tidak dipertimbangkan sebagai data time headway.

\section{STUDI PUSTAKA}

\section{II.1 Defenisi Time Headway}

Time headway adalah selisih waktu antar kendaraan yang beriringan yang melewati suatu titik tertentu dalam satu lajur (Salter, 1974). Karenanya time headway pada kenyataannya terdiri dari dua jenis waktu yaitu waktu okupansi (occupancy time) dan waktu antara (time gap), Gambar 1.1. Waktu okupansi adalah lamanya waktu fisik kendaraan melewati suatu titik pengamatan. Sedangkan waktu antara merupakan selisih waktu saat belakang kendaraan yang didepan melewati suatu titik pengamatan dengan saat ujung depan kendaraan yang mengikutinya melewati titik yang sama (May, 1990).

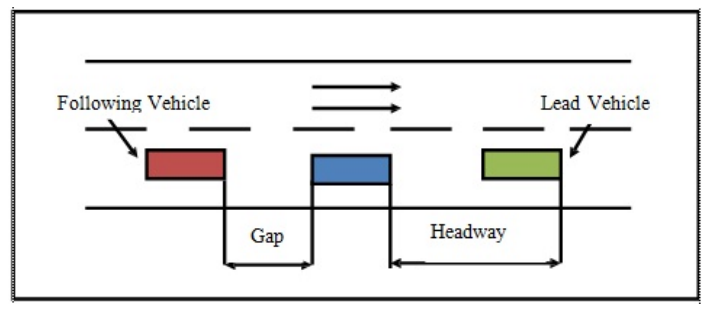

Gambar 1.1 Headway dan Gap

\section{IURNAL REKAYASA SIPIL}




\section{II.2 Distribusi Time Headway}

Menurut Sukowati (2004), distribusi time headway pada umumnya bervariasi untuk kondisi arus lalu lintas dilapangan, tergantung dengan tingkat kepadatan arus lalu lintas pada suatu jalan dan pada waktu tertentu. Umumnya arus lalu lintas dapat dibagi menjadi tiga kategori, yaitu kondisi arus lalu lintas tinggi, rendah, sedang.

\section{II.3 Model Distribusi}

Model distribusi time headway adalah model distribusi kontinu. Ada beberapa jenis model distribusi kontinu yang dapat digunakan untuk memperkirakan model distribusi ruas jalan yang akan ditentukan, seperti Tabel 2.1 berikut.

Tabel 2.1. Jenis Model Distribusi Kontinu

\begin{tabular}{|l|l|l|l|}
\hline No. & Jenis Model Distribusi & No. & Jenis Model Distribusi \\
\hline 1 & Beta & 25 & Laplace \\
\hline 2 & Bur & 26 & Levy \\
\hline 3 & Cauchy & 27 & Log-Gamma \\
\hline 4 & Chi-Square & 28 & Logistic \\
\hline 5 & Dagum & 29 & Log-Logostic \\
\hline 6 & Erlang & 30 & Lognormal \\
\hline 7 & Error & 31 & Log-Pearson 3 \\
\hline 8 & Error Function & 32 & Nakagami \\
\hline 9 & Exponential & 33 & Normal \\
\hline 10 & F Distribution & 34 & Pareto (First Kind) \\
\hline 11 & Fatigue Life & 35 & Pareto (Second Kind) \\
\hline 12 & Frechet & 36 & Pearson Type 5 \\
\hline 13 & Gamma & 37 & Pearson Type 6 \\
\hline 14 & Gen. Extreme Value & 38 & Pert \\
\hline 15 & Gen. Gamma & 39 & Phased Bi-Exponential \\
\hline 16 & Gen. Logistic & 40 & Phased Bi-Weibul \\
\hline 17 & Gen. Pareto & 41 & Power Function \\
\hline 18 & Gumbel Max & 42 & Rayleigh \\
\hline 19 & Gumbel Min & 43 & Reciprocal \\
\hline 20 & Hyporbolic Secant & 44 & Rice \\
\hline 21 & Inverse Gaussian & 45 & Uniform \\
\hline 22 & Johnson SB & 46 & Wakeby \\
\hline 23 & Johnson SU & 47 & Wibull \\
\hline 24 & Kumaraswamy & & \\
\hline & & & \\
\hline
\end{tabular}

\section{II.4 Kolmogorov-Smirnov Test}

Menurut Siregar (2010) Kolmogorov-Smirnov test digunakan untuk menguji "goodness of fit" antar distribusi sampel dan distribusi lainnya. Uji ini membandingkan serangkaian data pada sampel terhadap distribusi normal serangkaian nilai dengan mean dan standar deviasi yang sama. Singkatnya uji ini dilakukan untuk mengetahui kenormalan distribusi beberapa data.

\section{II.5 Uji Distribusi Data dengan Software Easyfit Professional 5.6}

Arwindy (2014) menjelaskan Software Easyfit Professional 5.6 merupakan suatu perangkat yang digunakan untuk membantu dalam pencocokan distribusi yang dibuat untuk memudahkan analisis probalitas data dalam simulasi. Perangkat ini dapat dengan mudah memilih distribusi yang terbaik 
sesuai data yang diberikan. Dalam simulasi, perangkat ini berguna untuk menemukan bentuk distribusi probalitas data empiris yang paling cocok untuk masing-masing variabel keadaan selanjutnya dibangkitkan bilangan acak sesuai dengan distribusi tersebut.

\section{II.6 Klasifikasi Jalan Menurut Medan Jalan}

Medan jalan di klasifikasikan berdasarkan kondisi sebagian besar kemiringan medan yang di ukur tegak lurus garis kontur (Ditjen Bina Marga, 1997).

Tabel 2.2. Klasifikasi Menurut Medan Jalan

\begin{tabular}{|c|l|c|c|}
\hline No. & Jenis Medan & Notasi & Kemiringan Medan (\%) \\
\hline 1. & Datar & D & $<3$ \\
\hline 2. & Berbukit & B & $3-25$ \\
\hline 3. & Pegunungan & G & $>25$ \\
\hline
\end{tabular}

\section{HASIL, ANALISA DATA DAN PEMBAHASAN}

\section{III.1 Pengumpulan Data Arus Lalu Lintas}

Pengumpulan data penelitian ini dilakukan dengan menggunakan kamera handycam yang diletakkan disisi ruas jalan yang telah ditetapkan. Untuk mendapatkan nilai time headway dari masing-masing segmen (arah arus lalu lintas kendaraan), dilakukan pencatatan dengan menggunakan stop data program. Adapun lokasi pengambilan data penelitian yaitu wilayah jalan berbukit yang mempunyai kemiringan jalan 9,922 \%, tepatnya di jalan lintas Padang Panjang Bukittinggi kilometer 5. Pengumpulan data dilakukan pada arus kendaraan yang padat (peak hour) berdasarkan survey pendahuluan.

Tabel 3.1. Volume Jam Sibuk Arus Lalu Lintas Total Selama Dua Hari Pengamatan

\begin{tabular}{|c|c|c|c|}
\hline \multirow{2}{*}{ No. } & \multirow{2}{*}{ Waktu } & \multicolumn{2}{|c|}{ Volume Total (Kend/jam) } \\
\cline { 3 - 4 } & & Sabtu & Minggu \\
\hline 1. & Pagi & 615 & 1184 \\
\hline 2. & Siang & 916 & 969 \\
\hline 3. & Sore & 1050 & 1349 \\
\hline
\end{tabular}

\section{III.2 Distribusi Frekwensi Data Time Headway}

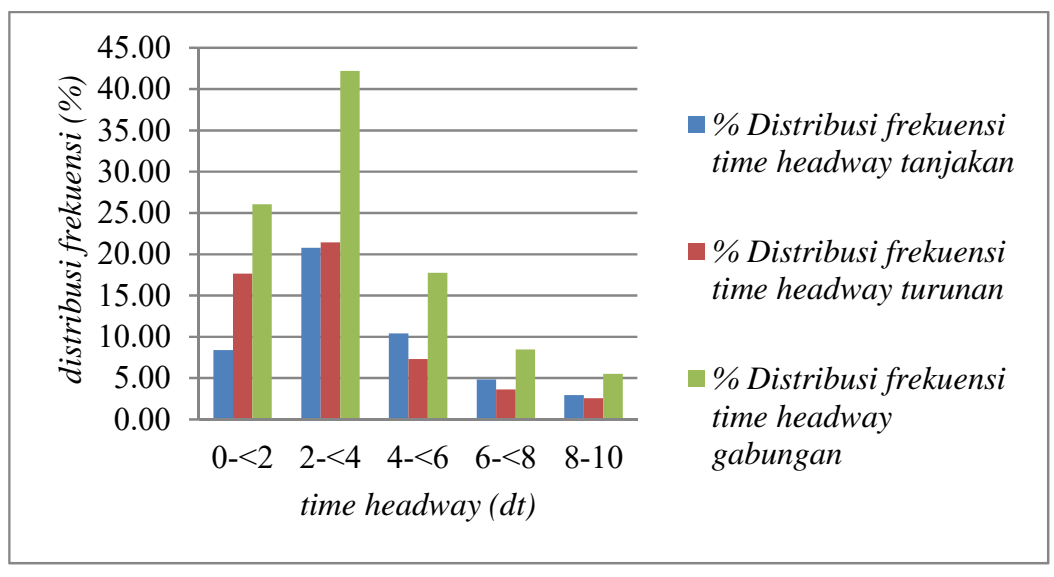

Gambar 3.1. Distribusi Frekuensi Time Headway (Sabtu)

\section{4 | JURNAL REKAYASA SIPIL}




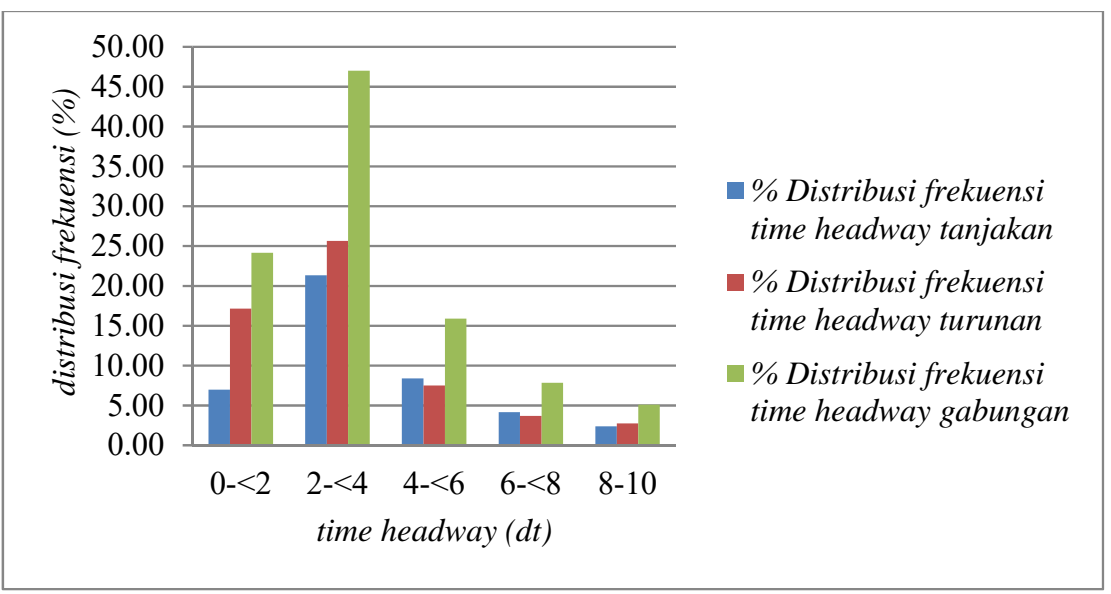

Gambar 3.2. Distribusi Frekuensi Time Headway (Minggu)

\section{III.3 Time Headway Rata-rata dan Standar Deviasi}

Tabel 3.2. Time Headway Rata-Rata Dan Standar Deviasi (Sabtu)

\begin{tabular}{|c|c|c|c|}
\hline No. & Uji & Tanjakan & Turunan \\
\hline 1. & Time headway rata-rata (dt) & 3,86 & 3,17 \\
\hline 2. & Standar deviasi $(\mathrm{dt})$ & 2,17 & 2,17 \\
\hline
\end{tabular}

Tabel 3.3. Time Headway Rata-Rata Dan Standar Deviasi (Minggu)

\begin{tabular}{|c|c|c|c|}
\hline No. & Uji & Tanjakan & Turunan \\
\hline 1. & Time headway rata-rata $(\mathrm{dt})$ & 3,59 & 3,00 \\
\hline 2. & Standar deviasi $(\mathrm{dt})$ & 1,89 & 1,89 \\
\hline
\end{tabular}

\section{III.4 Model Distribusi}

Tabel 3.4. Hasil Uji Model Distribusi Time Headway Menggunakan Easyfit (Sabtu)

\begin{tabular}{|c|c|c|c|c|}
\hline Jalur & Model & Parameter & Dmax & $\mathbf{P}$ \\
\hline Tanjakan & Beta & $\begin{array}{l}\alpha_{1}=2,290 \quad \alpha_{2}=7,668 \\
a=4,615 \times 10^{-17} \quad b=16,809 \\
f(x)=\frac{1}{B(2,290,7,668)} \frac{\left(x-\left(4,615 \times 10^{-17}\right)\right)^{2,290-1}(16,809-x)^{7,668-1}}{\left(16,809-\left(4,615 \times 10^{-17}\right)^{2,290+7,668-1}\right.} \\
\text { Dimana : } B=\text { fungsi Beta }\end{array}$ & 0,220 & 0,878 \\
\hline Turunan & Weibull & $\begin{array}{l}\alpha=1,546 \beta=3,551 \\
\gamma=0 \\
f(x)=\frac{1,546}{3,551}\left(\frac{x}{3,551}\right)^{1,546-1} \exp \left(-\left(\frac{x}{3,551}\right)^{1,546}\right)\end{array}$ & 0,206 & 0,919 \\
\hline
\end{tabular}

Berdasarkan Tabel 3.4 model distribusi terbaik hasil uji time headway untuk kondisi lalu lintas Hari Sabtu pada jalur tanjakan didapatkan model hasil uji yang terbaik adalah model Beta dengan nilai $\alpha_{1}=2,290, \alpha_{2}=7,668, a=4,615 \times 10^{-17}, b=16,809$, pada jalur turunan didapatkan model hasil uji yang terbaik adalah model Weibull dengan nilai $\alpha=1,546, \beta=3,551, \gamma=0$. 
Tabel 3.5. Hasil Uji Model Distribusi Time Headway Menggunakan Easyfit (Minggu)

\begin{tabular}{|l|l|l|c|c|}
\hline Jalur & Model & \multicolumn{1}{|c|}{ Parameter } & Dmax & P \\
\hline Tanjakan & Beta & $\begin{array}{l}\alpha_{1}=2,217 \quad \alpha_{2}=6,626 \\
a=2,895 \times 10^{-16} \quad b=15,046\end{array}$ & 0,248 & 0,776 \\
& & $\begin{array}{l}f(x)=\frac{1}{B(2,217,6,626)} \frac{\left(x-\left(2,895 \times 10^{-16}\right)\right)^{2,217-1}(15,046-x)^{6,626-1}}{\left(15,046-\left(2,895 \times 10^{-16}\right)^{2,217+6,626-1}\right.} \\
\text { Dimana }: B=\text { fungsi Beta }\end{array}$ & & \\
\hline Turunan & Cauchy & $\begin{array}{l}\sigma=0,703 \\
\mu=2,937\end{array}$ & 0,226 & 0,859 \\
& & $f(x)=\left(\pi 0,703\left(1+\frac{x-2,937}{0,703}\right)^{2}\right)^{-1}$ & & \\
\end{tabular}

Berdasarkan Tabel 3.5 model distribusi terbaik hasil uji time headway individual untuk kondisi lalu lintas Hari Minggu pada jalur tanjakan didapatkan model hasil uji yang terbaik adalah model Beta dengan nilai $\alpha_{1}=2,217, \alpha_{2}=6,626, a=2,895 \times 10^{-16}, b=15,046$, untuk jalur turunan didapatkan model hasil uji yang terbaik adalah model Cauchy dengan nilai $\sigma=0,703, \mu=2,937$.

\section{KESIMPULAN}

Hasil uji model distribusi time headway Hari Sabtu pada jalur tanjakan didapatkan model hasil uji yang terbaik adalah model Beta dengan nilai $\alpha_{1}=2,290, \alpha_{2}=7,668, a=4,615 \times 10^{-17}, b=16,809$, pada jalur turunan didapatkan model hasil uji yang terbaik adalah model Weibull dengan nilai $\alpha=$ $1,546, \beta=3,551, \gamma=0$.

Hasil uji model distribusi time headway Hari Minggu pada jalur tanjakan didapatkan model hasil uji yang terbaik adalah model Beta dengan nilai $\alpha_{1}=2,217, \alpha_{2}=6,626, a=2,895 \times 10^{-16}, b=15,046$, untuk jalur turunan didapatkan model hasil uji yang terbaik adalah model Cauchy dengan nilai $\sigma=0,703, \mu=2,937$.

\section{DAFTAR KEPUSTAKAAN}

Arwindy, F., Buulolo F., dan Rosmaini E. 2014. Analisis dan Simulasi Sistem Antrian pada Bank ABC. Saintia Matematika, Vol 2, No.2, pp. 147-162.

Ditjen Bina Marga. 1997, Tata Cara Perencanaan Geometrik Jalan Antar Kota. Departemen Pekerjaan Umum.

May, A.D. 1990. Fundamentals of Traffic Flow. Prentice Hall, Inc. Englewood Cliffs, New Jersey, USA.

Salter, R.J. 1974, Highway Traffic Analysis and Design, The Macmillan Press LTD, London.

Siregar,S. 2010. Statika Deskriptif untuk Penelitian. Jakarta : Rajawali Pers.

Sukowati, D.G. 2004, Karakteristik Time Headway Kendaraan di Jalan Tol dan Jalan Non Tol. Thesis Program Magister Teknik Sipil. Program Pasca Sarjana Universitas Diponegoro. (unpublished). 